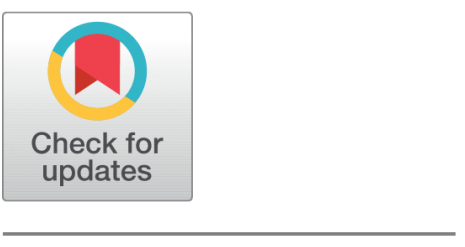

OPEN ACCESS

Received: 11.08.2020

Accepted: 28.10 .2020

Published: 20.11.2020

Editor: Dr. Natarajan Gajendran

Citation: Jainth S, Dahiya S, Kumar S (2020) Design and simulation of strip loaded and rib waveguide with integration of 2D material. Indian Journal of Science and Technology 13(40): 4262-4274. https://doi.org/ 10.17485/IJST/v13i40.1648

* Corresponding author.

sandhyajainth95@gmail.com

Funding: None

Competing Interests: None

Copyright: (c) 2020 Jainth et al. This is an open access article distributed under the terms of the Creative Commons Attribution License, which permits unrestricted use, distribution, and reproduction in any medium, provided the original author and source are credited.

Published By Indian Society for Education and Environment (iSee)

ISSN

Print: 0974-6846

Electronic: 0974-5645

\section{Design and simulation of strip loaded and rib waveguide with integration of 2D material}

\author{
Sandhya Jainth ${ }^{1}{ }^{*}$, Sandeep Dahiya ${ }^{1}$, Suresh Kumar ${ }^{2}$ \\ 1 Department of Electronics and Communication Engineering, Bhagat Phool Singh Mahila \\ Vishwavidyalaya, Sonipat, 131305, India \\ 2 Department of Electronics and Communication Engineering, Maharshi Dayanand \\ University, Rohtak, 124001, India
}

\section{Abstract}

Objective- To design Graphene-Silicon based rib waveguide and reduce the losses in the strip in order to meet the requirement for ultra-fast \& ultrahigh optical bandwidth communication and computing in integrated optical devices. Method -Propagation losses and effective refractive index are the two key parameters. In order to meet the objective, the effects of Graphene for manufacturing passive devices/components in the field of Integrated Photonic like integrated optical waveguide have been analysed by measuring the changes in propagation losses and effective refractive index of the silicon photonics devices for operating at different wavelengths. Findings- We have presented the design and simulation of SOI (Silicon-on-Insulator) platforms with 2D layer materials (graphene) which has been used along with their mode of propagation, effective refractive index $\left(\mathrm{n}_{e f f}\right)$, propagation losses $(\mathrm{dB} / \mathrm{cm})$ and varying wavelength range for optimum performance. In addition to this, we have also calculated the boundary limit for both the speed and bandwidth. We also reported the development of Silicon rib waveguide, Graphene-Silicon based rib waveguide and $\mathrm{Ge}$ on $\mathrm{SOI}$ with graphene later at the top of strip waveguide.Minimum loss of strip waveguide is $2.9 \mathrm{~dB} / \mathrm{cm}$ which has been obtained for Mid-IR wavelength generally used for high power mid- IR sensing.

Keywords: Silicon-on-Insulator; propagation loss; Effective Refractive Index (ERI); 2 D- material

\section{Introduction}

Photonics bears a fundamental concept with various technologies for the transmitting and signal processing of light. In fact, it is an engineering of processing the light, which is suitable for system implementations ${ }^{(1-3)}$. The importance of computational photonics, nanostructure \& physics, simulations of materials, and optoelectronics devices have arisen from the advancement of computational power ${ }^{(4)}$. An increasing demand of bandwidth in computing and signal processing, the vested limitations in metallic interconnections are gravely blusterous the future of conventional IC industry. Therefore, the photonics can provide a low- cost approach confirming the spout of high 
data rate transmission by replacing the original electronic integrated circuit with the photonics integrated circuits ${ }^{(5)}(6)$.

Integrated photonic component and devices are used for processing of light in optical structure called optical waveguide. Optical waveguide is the basic and very important element in the field of Integrated Photonics Technology. The waveguides are indispensable for communication and also for computing application, as these are immune to electromagnetic interference and induced cross talk as well as differential counters ${ }^{(7)}{ }^{(8)}$. The channel waveguide is a guiding factor in the form of different structure with different dimensions. In the channel waveguide or $2 \mathrm{D}$ waveguide, the high refractive index is surrounded by other media in the core region (where radiation is concentrated) ${ }^{(9)}$.

The channel waveguide allows the light confinement in both direction and propagates in only one direction. Unlike in planar waveguide, light confinement is only in one direction i.e. perpendicular to the interfaces. In this way, the radiation travelling in the $2 \mathrm{D}$ waveguide can propagate without suffering diffraction, which would otherwise lead to a power loss ${ }^{(10)}$. Therefore, to perform functions like Modulation, Switching, amplification, etc., the 2D or channel waveguide is the right choice for manufacturing integrated optical devices. The $2 \mathrm{D}$ waveguide is made from rare earth doped dielectric materials which are used for high power waveguide laser and amplification. Pump light can be injected along with amplified beam, from the side or the top. Even at the conditions of strong heating, the waveguide can help stabilize single mode laser beams with higher beam quality ${ }^{(11)}$.

The analysis of two types of channel waveguide including rib and strip waveguide with integration of 2D layer materials has been presented in the current research article. The rib waveguide guiding layer basically consists of dielectric slab with a strip superimposed on it.The strip waveguide is the part of the waveguide core ${ }^{(12-14)}$. The strip waveguide is made of three dielectric layers such as a substrate, a planar and a ridge. The planar waveguide (without strip) already offers optical light confinement in the vertical direction (y-axis) and apart from this the strip can provide localized optical light confinement under the strip, because of the increase local effective refractive index $\left(\mathrm{n}_{e f f}\right)^{(15-17)}$.

Graphene, a crystalline of allotropy of carbon with two dimensions, can exhibit a large diversity of physical behaviours ranging from wide band insulator to narrow gap semiconductor to semi-metal or metal. It offers aggravating opportunities for multifarious photonics and optoelectronics function enabling new conceptual photonics devices based on conventional bulk materials $^{(18)(19)}$.

Here, we have analysed the effects of Graphene on Integrated photonics devices to invent the passive devices/components like integrated optical waveguide by analysing \& measuring the change in propagation loss and effective refractive index of the silicon photonics devices at the different wavelength range ${ }^{(20)}$.

The geometrical analysis of integrated optical waveguide, the classification of channel waveguide on the basis of their geometries namely as rib and strip loaded waveguide are illustrated. Analysis of SOI (Silicon-on-Insulator) platforms with $2 \mathrm{D}$ layer materials (graphene) used along with their mode of propagation, effective refractive index $\left(\mathrm{n}_{e f f}\right)$, propagation losses $(\mathrm{dB} / \mathrm{cm})$ and wavelength range is presented. In our design simulation of $\mathrm{Ge}$ - SOI with graphene layer at the top of strip waveguide, we have obtained a minimum loss of $\sim 2.9 \mathrm{~dB} / \mathrm{cm}$ for Mid-IR wavelength which is used for high power midIR sensing and is much better in comparison with the propagation loss of $3.5 \mathrm{~dB} / \mathrm{cm}$ reportedin graphene- silicon waveguide at the Mid-IR wavelength ${ }^{(21)}$.

\section{Design of the silicon photonic rib waveguide}

The schematic structure of the silicon photonic Rib waveguide is shown in Figure 1 (a).

Guiding layer of the rib waveguide is basically consists of dielectric slab with strip superimposed on it.Thereby exhibits a similar structure as of the strip waveguide as part of the wave guiding core. Here the optical waveguide has been designed with different dimensions such as height, width, and thickness of the core and cladding. This photonic rib waveguide has been designed in 3D rectangular structure with a width of $700 \mathrm{~nm}$ and height $220 \mathrm{~nm}$ (ridge height of $70 \mathrm{~nm}$ ). Figure 1(b) depicts the schematic design of silicon Rib waveguide. It consists of silicon $(\mathrm{Si})$ based core \& cladding on a silica $\left(\mathrm{SiO}_{2}\right)$ based substrate. The simulation results will be obtained by applying the selected parameters as given in Table 1 below. The perspective view of Silicon rib waveguide is presented in Figure $1(\mathrm{C})$. 
(a)

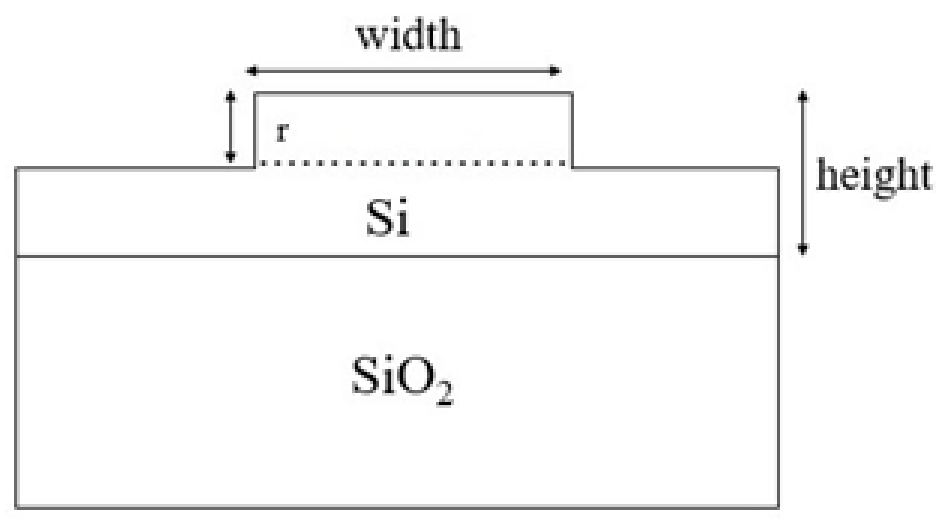

(b)

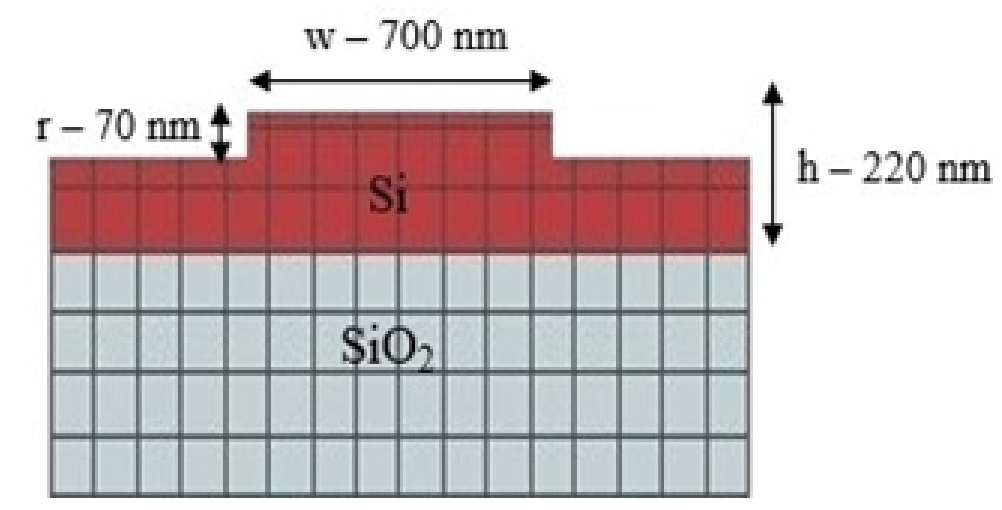

(c)

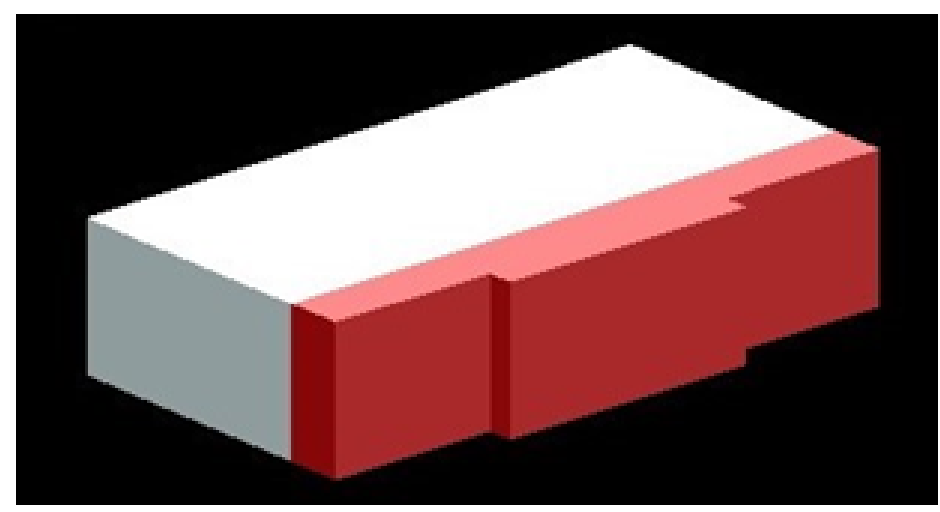

Fig 1. (a) Silicon photonic rib waveguide, (b) XY view of silicon photonic rib waveguide, (c) Perspective View of silicon rib waveguide

Table 1. Input parameters

\begin{tabular}{ll}
\hline Structure & $3 \mathrm{D}$ Rectangular \\
\hline Width & $700 \mathrm{~nm}$ \\
Height & $220 \mathrm{~nm}$ \\
Wavelength & $1.55 \mu \mathrm{m}$ \\
Materials & $\mathrm{Si}, \mathrm{SiO}_{2}$ \\
Simulation Solver & Eigen mode solver \\
Method & FDTD \\
\hline
\end{tabular}




\subsection{Simulation of rib waveguide with width variations}

Simulations have been performed in the state of Finite Difference Time Domain (FDTD) Method ${ }^{(22)}$, based on Lumerical Device Suit using MODE waveguide simulator. Simulated results obtained are shown in Figure 2 (a). The varation in effective refractive index $\left(\mathrm{n}_{e f f}\right)$ of the photonic Rib waveguide with the width ranging from $200 \mathrm{~nm}$ to $700 \mathrm{~nm}$. Each mode propagates through the waveguide with a phase velocity of $\mathrm{c} / \mathrm{n}_{e f f}$, where $\mathrm{c}$ is the speed of light in vaccum and $\mathrm{n}_{e f f}$ is the effective refractive index felt by that mode. The Effective Refractive Index depends upon the waveguide cross-section and waveguide materials ${ }^{(23)}$. Figure 2(b) exhibits the guided mode with $700 \mathrm{~nm}$ width and $220 \mathrm{~nm}$ height of silicon photonic rib waveguide at a wavelength of $1.55 \mu \mathrm{m}$. Figure 2(c)shows the mode loss for silicon rib photonic waveguide with a cross- section of $200 \times 220 \mathrm{~nm}$ at the wavelength of $1.55 \mu \mathrm{m}$.

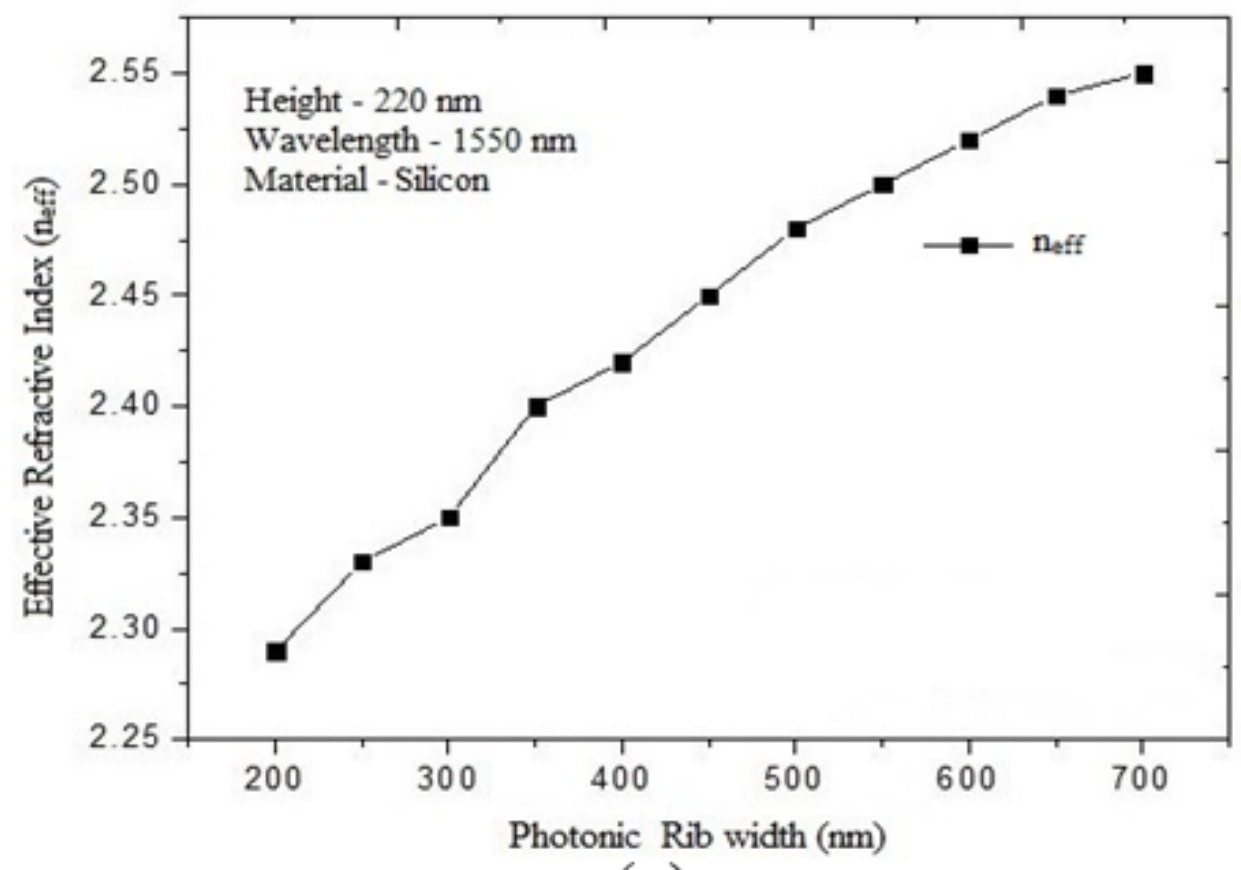

(a)

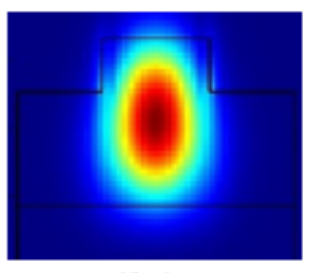

(b)

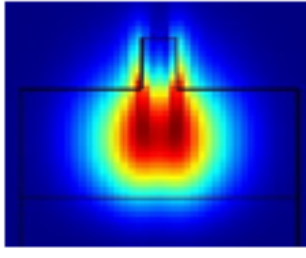

(c)

Fig 2. (a) Graph plot between rib width Vs Effective refractive index. (b) Guided mode, (c) Mode loss

\subsection{Simulation of rib waveguide with wavelength variations}

Figure 3 (a) shows the variation in effective refractive index $\left(\mathrm{n}_{e f f}\right)$ of the photonic rib waveguide by varying the wavelength from $1.55 \mu \mathrm{m}$ to $2.1 \mu \mathrm{m}$ with an interval of $50 \mathrm{~nm}$. Figure 3(b) exhibits the guided mode at a height of $220 \mathrm{~nm}$ and $700 \mathrm{~nm}$ width for the silicon photonic Rib waveguide operating at the wavelength of $1.55 \mu \mathrm{m}$. Figure 3 (c) shows the mode loss for silicon Rib photonic waveguide with a cross- section of $700 \times 220 \mathrm{~nm}$ at the wavelength of $2.1 \mu \mathrm{m}$. 


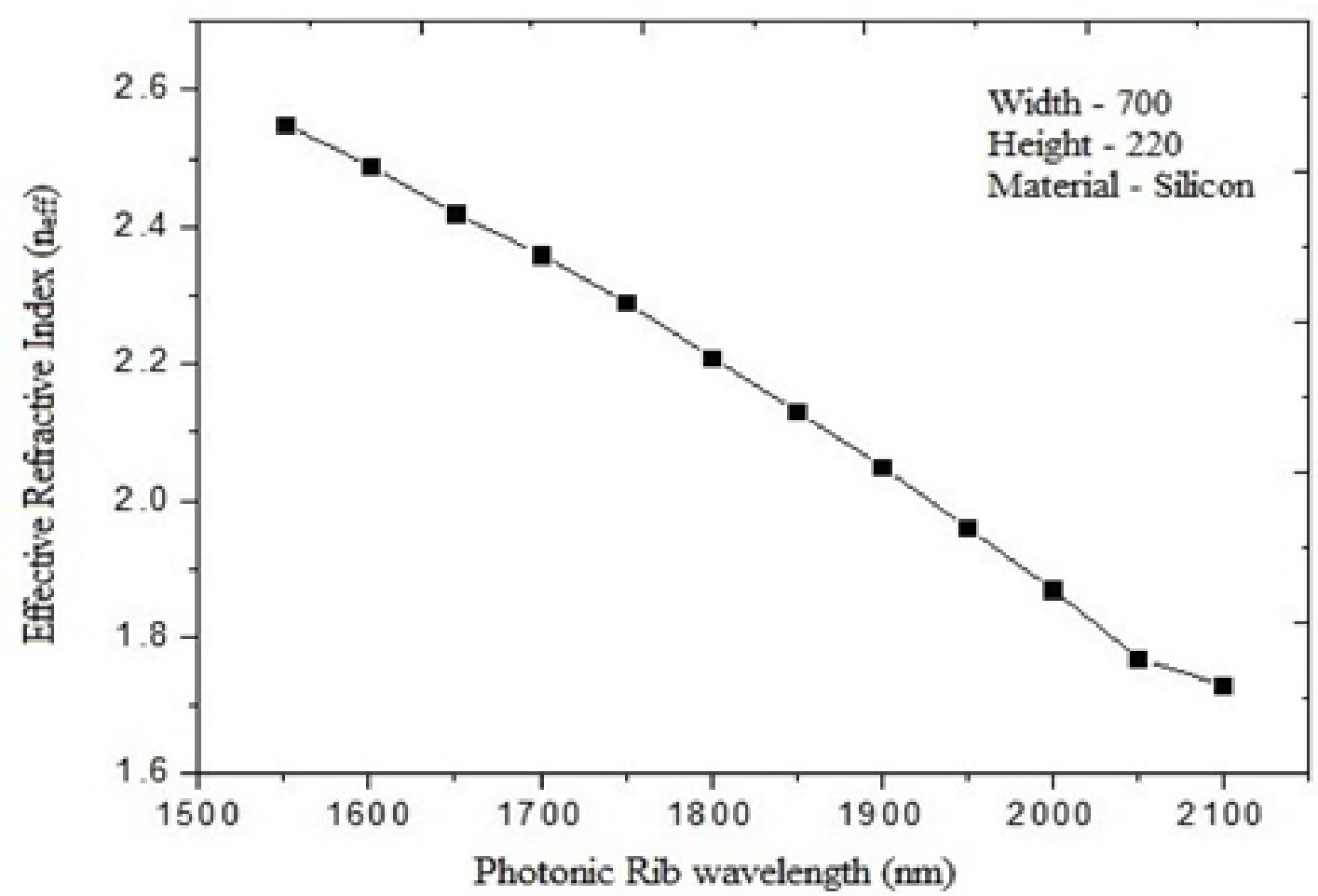

(a)
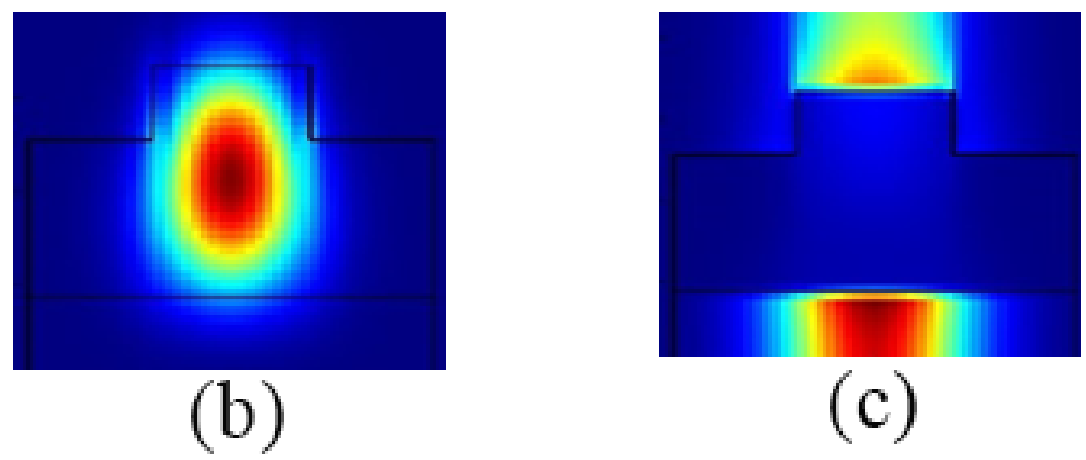

Fig 3. (a) Graph plot between rib wavelength Vs Effective refractive index, (b) Guided mode, (c) Mode loss

\subsection{Simulation results of rib waveguide with materials variations}

Figure 4 (a) shows the variation in effective refractive index $\left(\mathrm{n}_{\text {eff }}\right)$ of the photonic Rib waveguide of different materials like Germanium $(\mathrm{Ge})$, Silicon $(\mathrm{Si})$, Indium phoshide (InP), Silicon Nitride $\left(\mathrm{Si}_{3} \mathrm{~N}_{4}\right)$ for the structural parameter havinga width of $700 \mathrm{~nm}$, height $220 \mathrm{~nm}$ operating at the wavelength of $1.5 \mu \mathrm{m}$. Figure 4(b) shows the guided mode with a $220 \mathrm{~nm}$ height and $700 \mathrm{~nm}$ width with different material i.e. Germanium based Rib waveguide, Silicon based Rib waveguide, Indium Phosphide based Rib waveguide operating at the wavelength of $1.55 \mu \mathrm{m}$. Figure 4(c) shows the mode loss for Silicon Nitride based Rib waveguide with a cross- section of $700 \times 220 \mathrm{~nm}$ at the operating wavelength of $1.55 \mu \mathrm{m}$. 


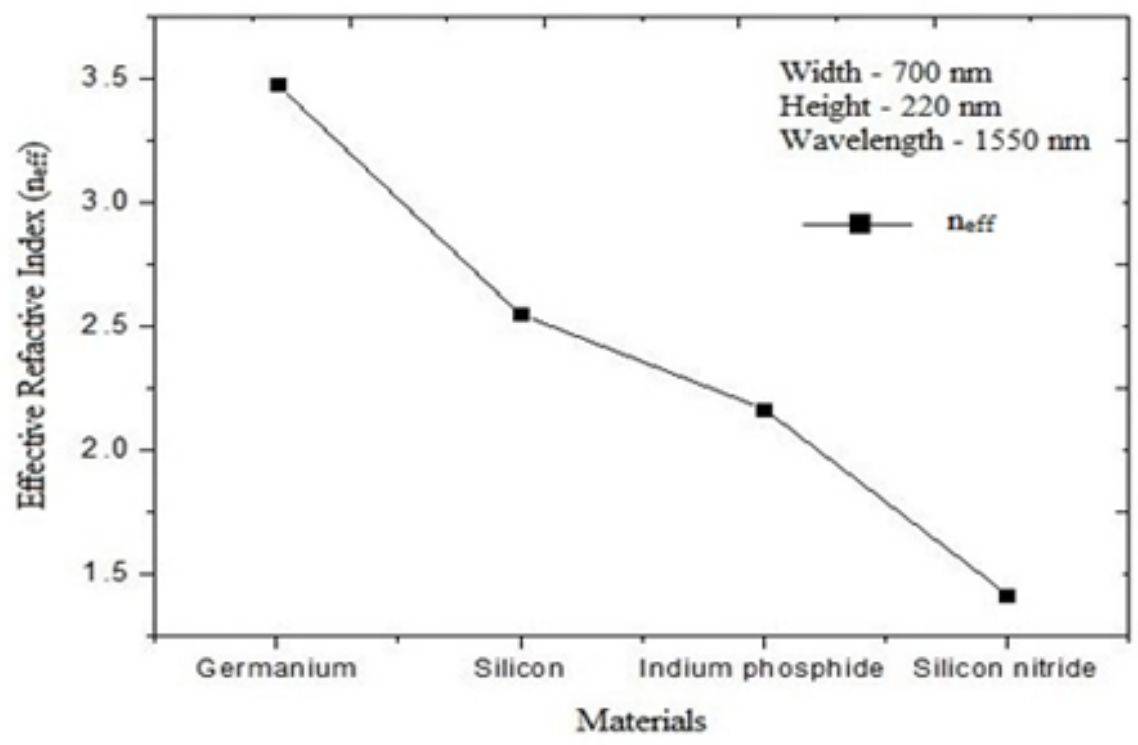

(a)

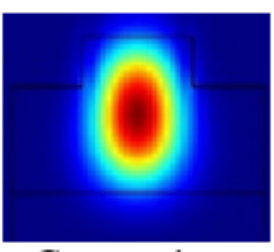

Germanium

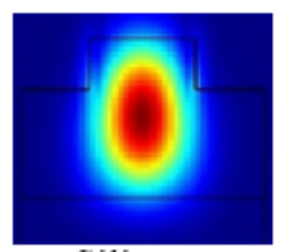

Silicon

(b)

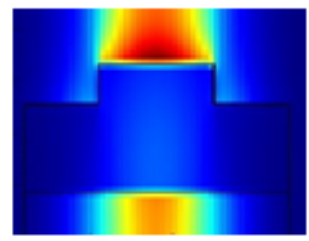

(c)

Fig 4. (a) Graph plot between material Vs Effective refractive index, (b) Guide mode with Germanium, Silicon and Indium Phosphide, (c) Mode loss with Silicon Nitride

\section{Design of the Graphene Silicon based rib waveguide}

The schematic structure of the Graphene-Silicon based photonic rib waveguide is shown in Figure 5 (a).

The optical Graphene-Silicon based Rib waveguide has been designed in 3D and 2D rectangular structure with a width of $550 \mathrm{~nm}$, height $220 \mathrm{~nm}$ (having ridge height of $70 \mathrm{~nm}$ ) and $0.03 \mathrm{~nm}$ thickness of graphene layer. The schematic design of silicon Rib waveguide is presented in Figure 5(b). It contains silicon $(\mathrm{Si})$ based core \& cladding, silica $\left(\mathrm{SiO}_{2}\right)$ based substrate and Graphene atomic layer which is placed at the top of the rib waveguide covering the fundamental mode area of the silion rib. To obtain the simulation result we have chosen Eigenmode solver in Lumerical MODE Finite Difference IDE-Layout. Eigenmode simulation solver is used for calculations of modes. Tables 2 and 3 shows the chosen parameters for simulating the design. 


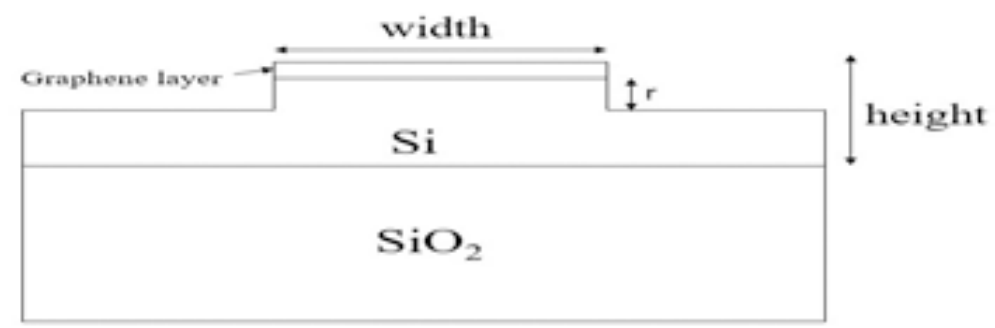

(a)

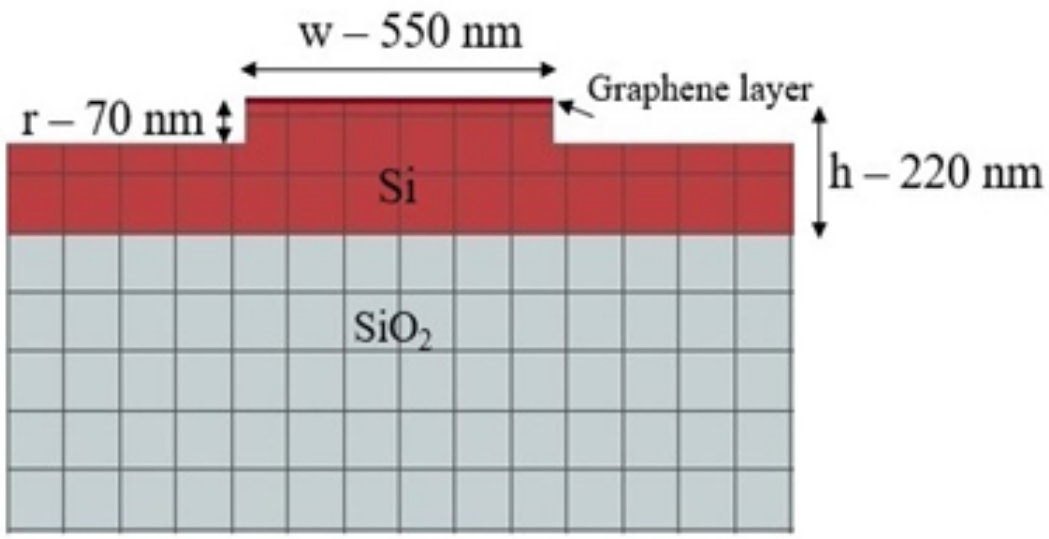

(b)

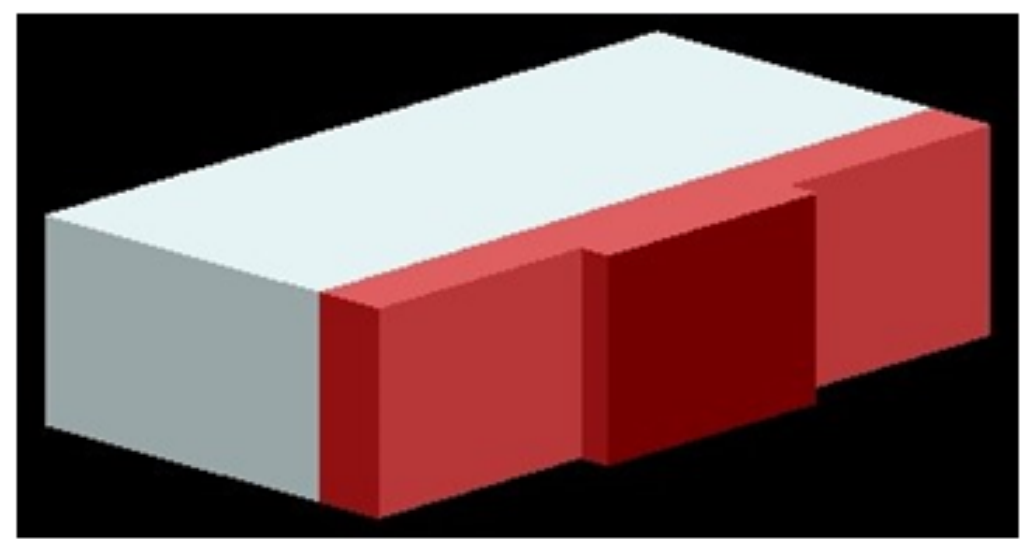

(c)

Fig 5. (a) Silicon photonic rib waveguide, 5 (b) XY view of Graphene - Silicon based Photonic rib waveguide, (c) Perspective view of Graphene - Silicon rib waveguide

Table 2. Input parameters

\begin{tabular}{ll}
\hline Structure & $3 \mathrm{D}$ and 2D Rectangular \\
\hline Width & $550 \mathrm{~nm}$ \\
Height & $220 \mathrm{~nm}$ \\
Wavelength & $1.55 \mu \mathrm{m}$ \\
Materials & $\mathrm{Si}, \mathrm{SiO}_{2}$, Graphene \\
Simulation Solver & Eigen mode solver \\
Method & FDTD \\
\hline
\end{tabular}


Table 3. Properties of Graphene

\begin{tabular}{ll}
\hline Thickness of Graphene atomic layer $(\mathrm{nm})$ & 0.03 \\
\hline Chemical Potential $(\mathrm{eV})$ & 0.6 \\
Scattering rate $(\mathrm{eV})$ & 0.00051423 \\
Temperature K & 300 \\
Conductivity scaling & 1 \\
\hline
\end{tabular}

The design has been made with dimensions of Silicon Photonic rib waveguide having width $-550 \mathrm{~nm}$, height $-220 \mathrm{~nm}$ (with ridge height $(\mathrm{r})=70 \mathrm{~nm})$ and $0.3 \mathrm{~nm}$ thickness of the graphene layer.

\subsection{Simulation results of Graphene - Silicon based rib waveguide with Chemical Potential variations}

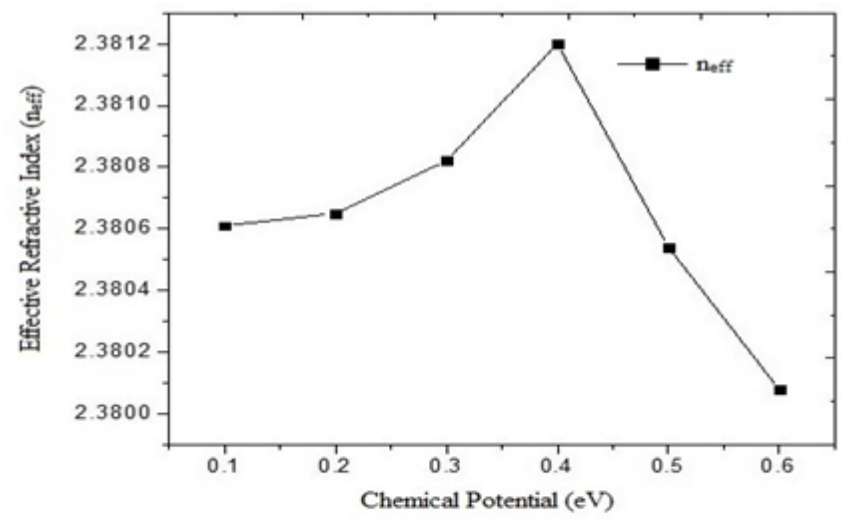

(a)

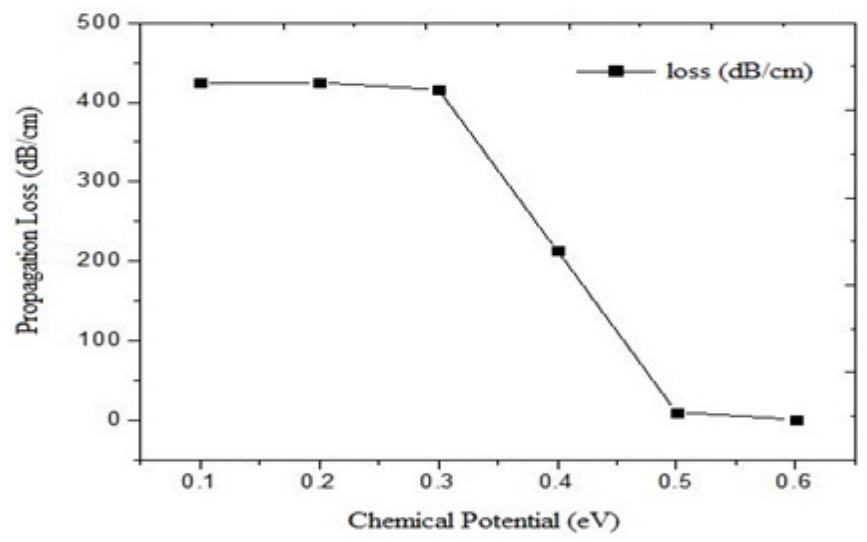

(b)

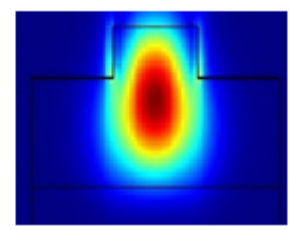

(c)

Fig 6. (a) Graph plot between chemical potential Vs Effective refractive index, (b) Graph plot between chemical potential Vs Propagation loss, (c) Effective mode area of Graphene - Silicon based rib waveguide 
A silicon photonic rib waveguide superimpose with graphene layer is presented for obtaining the afore improvement in the execution of high sensing for sensor. The performance will be analysed using 3D FDTD method maxwel solver for desiging, eplication \& optimization of integrated photonics device's process and material implicating wavelength scale framework.

The Effective Mode Index (EMI) variations for TE mode under chemical potentials has been presented in Figure 6 (a). Propagation variations under different chemical potentials and the graphene's chemical potential varies from 0.1 to $0.6 \mathrm{eV}$ as shown in Figure 6(b). Effective mode area of graphene-silicon rib waveguide with a cross- section of $550 \mathrm{x} 220 \mathrm{~nm}$ at the wavelength of $1.55 \mu \mathrm{m}$ has been presented in Figure 6(c).

Table 4. Calculated modes and propagation loss of the proposed Graphene - Silicon based rib waveguide.

\begin{tabular}{llllllll}
\hline $\begin{array}{l}\text { Chemical } \\
\begin{array}{l}\text { Potential } \\
(\mathrm{eV})\end{array}\end{array}$ & $\begin{array}{l}\text { Width } \\
(\mathrm{nm})\end{array}$ & height $(\mathrm{nm})$ & $\begin{array}{l}\text { Wavelength } \\
(\mu \mathrm{m})\end{array}$ & & Materials & $\begin{array}{l}\text { Thickness } \\
\text { of Graphene } \\
\text { later }(\mathrm{nm})\end{array}$ & $\begin{array}{l}\text { Obtained Effective } \\
\text { Refractive } \\
\left(\mathrm{n}_{\text {eff }}\right) \text { values }\end{array}$ \\
\hline 0.1 & 550 & 220 & 1.55 & $\mathrm{Sio}_{2}, \mathrm{Si}, \mathrm{Graphene}$ & 0.03 & 2.380615 & $\begin{array}{l}\text { Propagation } \\
\text { loss }(\mathrm{dB} / \mathrm{cm})\end{array}$ \\
0.2 & 550 & 220 & 1.55 & $\mathrm{Sio}_{2}, \mathrm{Si}, \mathrm{Graphene}$ & 0.03 & 2.380656 & 424.92 \\
0.3 & 550 & 220 & 1.55 & $\mathrm{Sio}_{2}, \mathrm{Si}, \mathrm{Graphene}$ & 0.03 & 2.380829 & 416.19 \\
0.4 & 550 & 220 & 1.55 & $\mathrm{Sio}_{2}, \mathrm{Si}, \mathrm{Graphene}$ & 0.03 & 2.381202 & 213.33 \\
0.5 & 550 & 220 & 1.55 & $\mathrm{Sio}_{2}, \mathrm{Si}, \mathrm{Graphene}$ & 0.03 & 2.380545 & 10.026 \\
0.6 & 550 & 220 & 1.55 & $\mathrm{Sio}_{2}, \mathrm{Si}, \mathrm{Graphene}$ & 0.03 & 2.380089 & 1.1469 \\
\hline
\end{tabular}

The best obtained values of effective refractive index is 2.3 at a propagation loss of $1.45 \mathrm{~dB} / \mathrm{cm}$ operating at the wavelength of $1550 \mathrm{~nm}$. All these simulated results are based on the incident light having wavelengh, $\lambda=1550 \mathrm{~nm}$ and $\mathrm{T}=300 \mathrm{~K}$.

\section{Design of Graphene-on-Germanium SOI strip waveguide}

The schematic structure of the Graphene-on-Germanium-SOI based photonic strip waveguide is shown in Figure 7 (a) below.

This strip waveguide consists of 3 dielectric layers namely substrate, planar and ridge. Whereas, the planar (without strip) already offers optical light confinement in the vertical direction (y-axis). Apart from this, it also provides localized optical light confinement due to the increased local $\mathrm{n}_{e f f}$. The optical Graphene-on-Germanium-SOI strip waveguide has been designed in 3D and 2D rectangular structure with a width of $500 \mathrm{~nm}$, height of $220 \mathrm{~nm}$ (with ridge height of $75 \mathrm{~nm}$ ) and thickness of Graphene layer as $0.03 \mathrm{~nm}$. Figure 7(b) shows the schematic design of Graphene-on-Germanium-SOI based photonic strip waveguide. It contains silicon $(\mathrm{Si})$ for core and cladding, silica $\left(\mathrm{SiO}_{2}\right)$ for Substate, germanium $(\mathrm{Ge})$ for strip and then applies a Graphene atomic layer, which is placed on the top of the Strip waveguide in order to cover the fundamental mode area of the Germanium strip. Parameters selected for simulation are given in Tables 5 and 6.

Table 5. Input parameters

\begin{tabular}{ll}
\hline Structure & $3 \mathrm{D}$ and 2D Rectangular \\
\hline Width & $500 \mathrm{~nm}$ \\
height & $220 \mathrm{~nm}$ \\
Wavelength & $1.55 \mu \mathrm{m}$ \\
Materials & $\mathrm{Si}, \mathrm{SiO}_{2}, \mathrm{Graphene}$ \\
Simulation Solver & Eigen mode solver \\
Method & FDTD \\
\hline
\end{tabular}

Table 6. Parameters used for Graphene

\begin{tabular}{ll}
\hline Thickness of Graphene atomic layer(nm) & 0.03 \\
\hline Chemical Potential $(\mathrm{eV})$ & 0.6 \\
Scattering rate $(\mathrm{eV})$ & 0.00051423 \\
Temperature K & 300 \\
Conductivity scaling & 1 \\
\hline
\end{tabular}




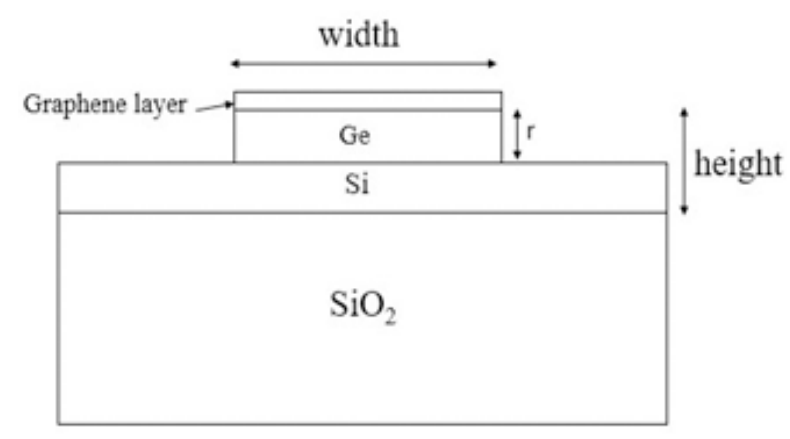

(a)

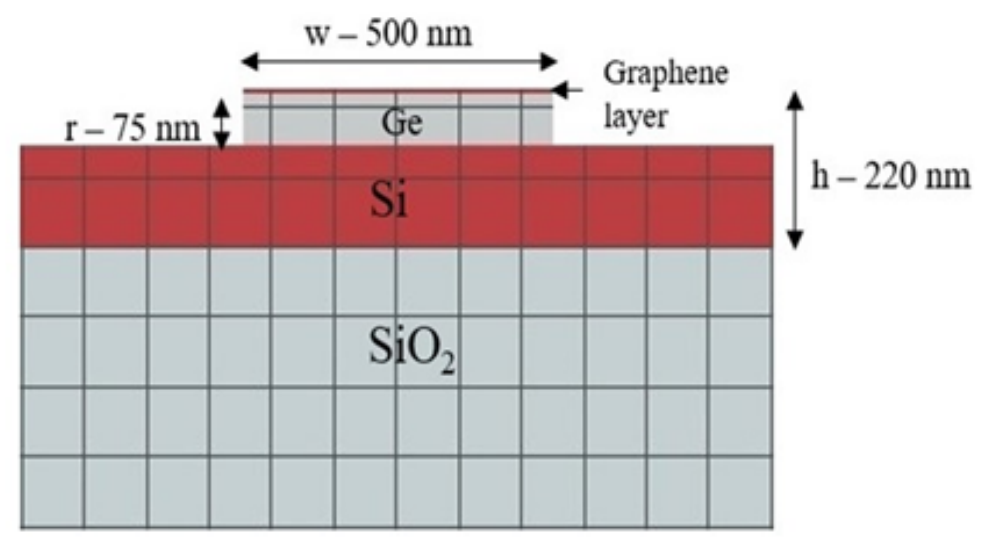

(b)

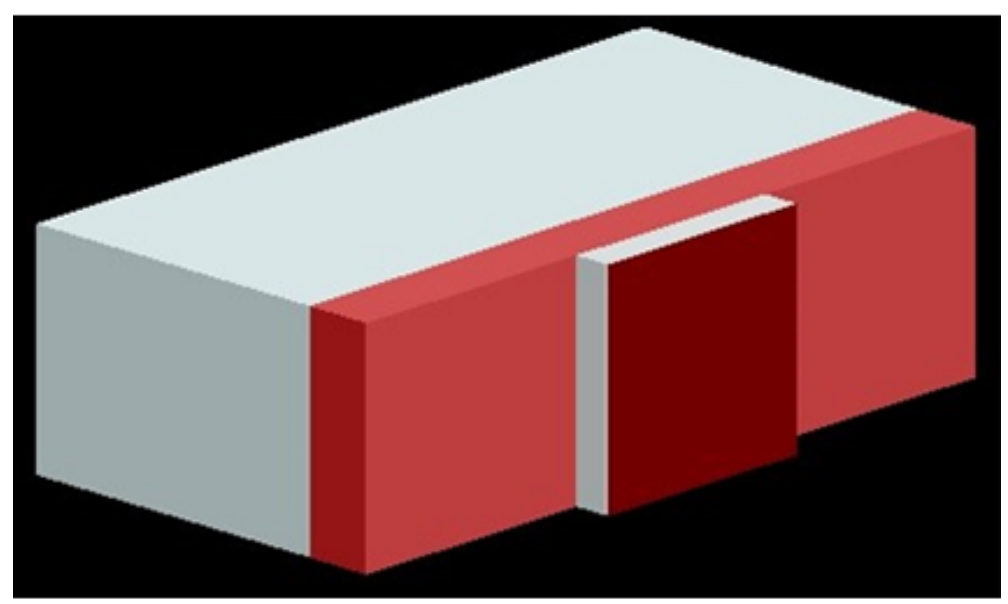

(c)

Fig 7. (a) Graphene-on-Germanium-SOI based photonic strip waveguide, (b) XY view of Graphene-on-Germanium-SOI Strip waveguide, (c) Perspective View of Graphene-on-Germanium-SOI strip waveguide 
The dimensions of Germanium-on-Silicon based strip waveguide with a 2D structure layer having a width of $500 \mathrm{~nm}$, height of $220 \mathrm{~nm}$ and thickness of graphene as $0.3 \mathrm{~nm}$. We have applied graphene sheet as an atomic layer on the top of the waveguide to cover the fundamental mode area of Gemanium Strip. The schematic design of Graphene-on-Germanium-SOI based photonic Strip waveguide is shown in Figure $7(\mathrm{c})$. It contains silicon ( $\mathrm{Si}$ ) for core and cladding, Silica $\left(\mathrm{SiO}_{2}\right)$ for substate, Germanium (Ge) for strip and then applies a Graphene atomic layer which is placed on the top of the strip waveguide.

\subsection{Simulation results of Graphene-on-Germanium-on-SOI strip waveguide with wavelength variations}

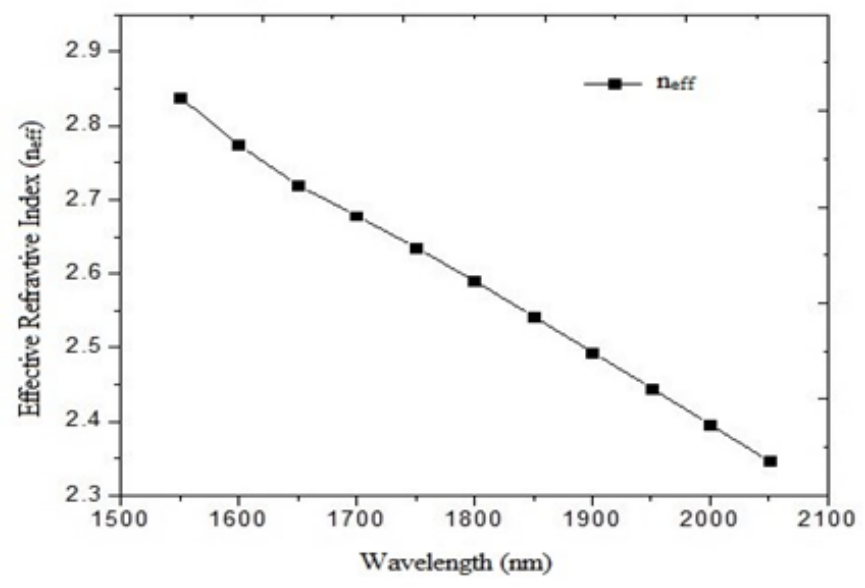

(a)

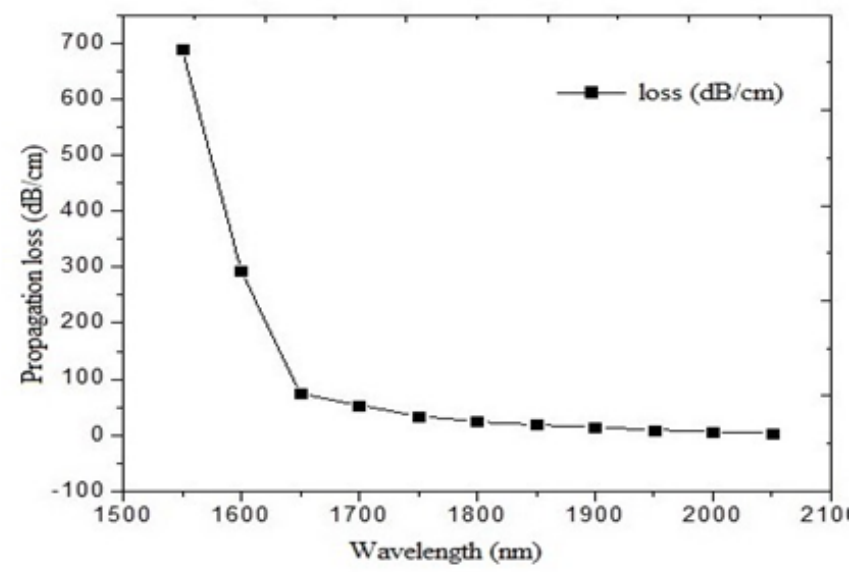

(b)

(c)

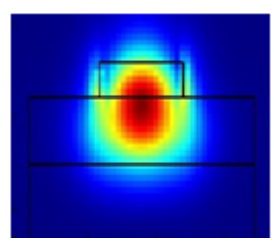

Fig 8. (a) Graph plot between wavelength Vs Effective refractive index, (b) Graph plot between wavelength Vs propagation loss, (c) Effective mode area of Graphene-on-Germanium-on-SOI strip waveguide.

It shows the variation in effective refractive index $\left(\mathrm{n}_{e f f}\right)$ of the graphene-on-germanium-on-SOI strip waveguide operating at a wavelength from $1550 \mathrm{~nm}$ to $2050 \mathrm{~nm}$ with an interval of $50 \mathrm{~nm}$ has been presented in Figure 8 (a). Propagation variations and losses at different wavelength from $1550 \mathrm{~nm}$ to 2050 are shown in Figure 8(b). The effective mode area of graphene-germanium- 
on-silicon strip waveguide with cross- section $500 \times 220 \mathrm{~nm}$ at the wavelength $2.05 \mu \mathrm{m}$ has been presented in Figure $8(\mathrm{c})$. The parameters chosen for simulations are shown in Table 7.

Table 7. Modes and propagation loss of proposed waveguide of the Graphene-Germanium-SOI Sstrip waveguide.

\begin{tabular}{|c|c|c|c|c|c|c|c|}
\hline $\begin{array}{l}\text { with Width } \\
\text { variation } \\
(\mathrm{nm})\end{array}$ & $\begin{array}{l}\text { height } \\
(\mathrm{nm})\end{array}$ & $\begin{array}{l}\text { Wavelength } \\
(\mu \mathrm{m})\end{array}$ & Materials & $\begin{array}{l}\text { Thickness } \\
\text { of Graphene } \\
\text { later (nm) }\end{array}$ & $\begin{array}{l}\text { Chemical } \\
\text { Poten- } \\
\text { tial } \\
(\mathrm{eV})\end{array}$ & 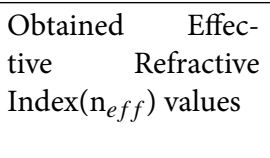 & $\begin{array}{l}\text { Propagation } \\
\text { loss } \\
(\mathrm{dB} / \mathrm{cm})\end{array}$ \\
\hline 500 & 220 & 1.55 & $\mathrm{Sio}_{2}, \mathrm{Si}, \mathrm{Ge}$, Graphene & 0.03 & 0.6 & 2.83 & 688.0 \\
\hline 500 & 220 & 1.6 & $\mathrm{Sio}_{2}, \mathrm{Si}, \mathrm{Ge}, \mathrm{Graphene}$ & 0.03 & 0.6 & 2.77 & 293.4 \\
\hline 500 & 220 & 1.65 & $\mathrm{Sio}_{2}, \mathrm{Si}, \mathrm{Ge}, \mathrm{Graphene}$ & 0.03 & 0.6 & 2.71 & 74.33 \\
\hline 500 & 220 & 1.7 & $\mathrm{Sio}_{2}, \mathrm{Si}, \mathrm{Ge}, \mathrm{Graphene}$ & 0.03 & 0.6 & 2.67 & 53.06 \\
\hline 500 & 220 & 1.75 & $\mathrm{Sio}_{2}, \mathrm{Si}, \mathrm{Ge}$, Graphene & 0.03 & 0.6 & 2.63 & 34.34 \\
\hline 500 & 220 & 1.8 & $\mathrm{Sio}_{2}, \mathrm{Si}, \mathrm{Ge}, \mathrm{Graphene}$ & 0.03 & 0.6 & 2.59 & 23.80 \\
\hline 500 & 220 & 1.85 & $\mathrm{Sio}_{2}, \mathrm{Si}, \mathrm{Ge}$, Graphene & 0.03 & 0.6 & 2.54 & 18.57 \\
\hline 500 & 220 & 1.9 & $\mathrm{Sio}_{2}, \mathrm{Si}, \mathrm{Ge}$, Graphene & 0.03 & 0.6 & 2.49 & 13.94 \\
\hline 500 & 220 & 1.95 & $\mathrm{Sio}_{2}, \mathrm{Si}, \mathrm{Ge}, \mathrm{Graphene}$ & 0.03 & 0.6 & 2.44 & 98.44 \\
\hline 500 & 220 & 2.00 & $\mathrm{Sio}_{2}, \mathrm{Si}, \mathrm{Ge}$, Graphene & 0.03 & 0.6 & 2.39 & 6.192 \\
\hline 500 & 220 & 2.05 & $\mathrm{Sio}_{2}, \mathrm{Si}, \mathrm{Ge}, \mathrm{Graphene}$ & 0.03 & 0.6 & 2.34 & 2.927 \\
\hline
\end{tabular}

The couple of plots i.e. 2D plot and 3D plot have been obtained. 3D Far field plot shows the far field intensity pattern with a typical donut type shape as shown in Figures. Both the plots are obtained at the same frequency.

\section{Conclusion}

Integrated optical devices are designed to meet and foresee the futuristic requirements for ultra-fast \& ultra-high optical bandwidth communication and computing. Graphene has been extensively used for designing various types of photonics and optoelectronic devices, and has been found to be operating at an enormously broad spectral enlarging from the ultraviolet, visible \& Near-IR, Mid-IR, Far-IR range. It also covers the terahertz and microwave regions. The classification of channel waveguide on the basis of their geometries namely rib waveguide and strip waveguide have been illustrated in the current research. Analysis of SOI (Silicon-on-Insulator) platforms with 2D layer materials (graphene) used along with their mode of propagation, effective refractive index $\left(\mathrm{n}_{e f f}\right)$, propagation losses $(\mathrm{dB} / \mathrm{cm})$ and wavelength variation has been presented. In addition to this we have also calculated the optimum performance limit both for speed and bandwidth. A minimum loss of strip waveguide achieved is $\sim 2.9 \mathrm{~dB} / \mathrm{cm}$ in our Ge-on-SOI with graphene layer at the top of the core for Mid-IR wavelength. Thereby we have obtained an improvement of approx. $22 \%$ from the earlier reported loss on $3.5 \mathrm{~dB} / \mathrm{cm}$.

\section{References}

1) Tansu N. Photonics-Advances in Fundamental Science and Engineering Technologies of Light. Open access Photonics. 2014;1:1-8. Available from: https://doi.org/10.3390/photonics1010001.

2) Stievater TH, Pruessner MW. Suspended Photonic Waveguide Devices. OSA-Applied Optics. 2015.

3) Bettotti P. Hybrid Materials for Integrated Photonics. 2014. Available from: https://dx.doi.org/2014/891395.

4) Abel S, Horst F. Silicon Photonics Integration technologies for future Computing System. IEICE. IEICE. 2019.

5) Kum H, Lee D, Kong W, Kim H, Park Y, Kim Y, et al. Epitaxial growth and layer-transfer techniques for heterogeneous integration of materials for electronic and photonic devices. Nature Electronics. 2019;2(10):439-450. Available from: https://dx.doi.org/10.1038/s41928-019-0314-2.

6) Rumley S, Bahadori M. Optical Interconnects for extreme scale computing systems. Elsevier-Parallel Computing. 2017. Available from: http://dx.doi.org/ 10.1016/j.parco.2017.2.001.

7) Komljenovic T, Huang D, Pintus P, Tran MA, Davenport ML, Bowers JE. Photonic Integrated Circuits Using Heterogeneous Integration on Silicon. Proceedings of the IEEE. 2018;106(12):2246-2257. Available from: https://dx.doi.org/10.1109/jproc.2018.2864668.

8) Hongtaolin Z. Mid-infrared integrated photonics on silicon: A perspective. Nanophotonics. 2018;7(2):393-420. Available from: http://doi.org/10.1515/ nanoph-2017-0085.

9) Dong B, Guo X, Ho CP, Li B, Wang H, Lee C, et al. Silicon-on-Insulator Waveguide Devices for Broadband Mid-Infrared Photonics. IEEE Photonics Journal. 2017;9(3):1-10. Available from: https://dx.doi.org/10.1109/jphot.2017.2692039.

10) Alagrappan G, ChingEngPng. Universal deep learning representation of effective refractive index for photonics channel waveguides. Journal of Optical Society of America. 2019. Available from: http://doi.org/10.1364/JOSAB.36.002636.

11) Li YZQ, Zhang. 6.5 GHz Q-Switched Mode locked Waveguide Laser Based on Two-Dimensional Materials as Saturable Absorber. OSA-Optics Express. 2018. Available from: http://doi.org/10.1364/OE.26.011321. 
12) Butt MA, Khonina SN. Modelling of Rib channel waveguides based on Silicon-on-Sapphire at $4.67 \mu \mathrm{m}$ wavelength for evanescent field gas absorption sensor. Elsevier - Optik. 2018. Available from: http://doi.org/10.1016/j.ijelo.2018.04.134.

13) Ma T, Yuan J. Graphene-Coated Two-layer Dielectric Loaded Surface Plasmon Polarization Rib Waveguide with Ultra-Long Propagation Length and Ultra - High Electro-Optics Wavelength Tunning. IEEE Access. 2020. Available from: https://doi.org/10.1109/ACCESS.2020.2999395.

14) Yusof R, Ali N, Kolenderski P, Slowik K, Hambali NAMA. Comparative Studies of Rib Waveguide Material for Quantum Communication Application. IOP Conference Series: Materials Science and Engineering. 2019;551. Available from: https://dx.doi.org/10.1088/1757-899x/551/1/012018.

15) Awal MA, Ahmed Z, Talukder MA. An efficient plasmonic photovoltaic structure using silicon strip-loaded geometry. Journal of Applied Physics. 2015;117(6). Available from: https://dx.doi.org/10.1063/1.4907873.

16) Butt MA, Kozlova ES. Single mode $\mathrm{ZnO} / \mathrm{Al} 2 \mathrm{O} 3$ Strip loaded waveguide at $633 \mathrm{~nm}$ at visible wavelength. In: and others, editor. 3rd international conference "Information technology and nanotechnology. 2017. Available from: https://doi.org/10.18287/1613-0073-2017-1900-126-129.

17) Butt MA, Khonnia SN. Enhancement of evanescent field ratio in a silicon strip waveguide by incorporating a thin metal film. Laser Physics. 2019. Available from: http://doi.org/10.1088/1555-6611/ab1414.

18) Hao R, Ye Z, Gu Y, Peng X, Chen H, Li E. Large modulation capacity in graphene-based slot modulators by enhanced hybrid plasmonic effects. Scientific Reports. 2018;8(1). Available from: https://dx.doi.org/10.1038/s41598-018-34914-6.

19) Qu Z, Nedeljkovic. Waveguide Integrated Graphene Mid-Infrared Photodector. In: and others, editor. SPIE OPTO. 2018. Available from: https: //doi.org/10.1117/12.2290476.

20) Youngblood N, Anugrah Y. Multifunctional Graphene Optical Modulator and Photodector Integrated on Silicon Waveguide. Americal Chemical Society. Americal Chemical Society. 2014. Available from: http://dx.doi.org/10.1021/nl500712u.

21) Malik A, Muneeb M. Germanium - on - Silicon Mid-Infrared Arrayed Waveguide Grating Multiplexer. IEEE- Photonics Technology Letters. 2013. Available from: https://doi.org/10.1109/LPT.2013.2276479.

22) Ya-Chilu, Chang K. Performance Comparison Between FDTD and FEM for the Simulation of Plasmonic Waveguide Operating at Optical Communication Frequency. IEEE. 2013.

23) Kim R, Chung K, Kim JY, Nam Y, Park SHK, Shin J. Metal nanoparticle array as a tunable refractive index material over broad visible and infrared wavelengths. ACS Photonics. 2018;5(4):1188-1195. Available from: https://dx.doi.org/10.1021/acsphotonics.7b01497. 